\title{
A regulamentação da responsabilidade social empresarial: entre a ortodoxia e heteronomia normativa
}

\author{
Regulation of corporate social responsibility: between orthodoxy and \\ normative heteronomy
}

\author{
Philippe Dall' Agnol \\ Centro Universitário de Brasília - UniCEUB \\ Doutorando em Direito \\ Procurador do Estado de Goiás \\ Goiânia / GO / Brasil \\ philippedallagnol@gmail.com \\ (i) Paulo Afonso Cavichioli Carmona \\ Centro Universitário de Brasília - UniCEUB \\ Doutor em Direito \\ Juiz de Direito - TJDFT \\ Brasília / DF / Brasil \\ paulo.carmona@ceub.edu.br
}

\begin{abstract}
Resumo: A Responsabilidade Social da Empresa é objeto de estudo nas mais diversas áreas do conhecimento, com o ponto comum de análise do papel da empresa face às perspectivas advindas da globalização e das inovações do século XXI. Ao Direito compete examinar as iniciativas de normatização da RSE, com destaque para a força normativa de instrumentos regulamentadores não estatais e para a adequação e necessidade da edição de normas gerais e abstratas provenientes do Estado. Para tanto, é imperioso ao objeto de estudo delinear os principais instrumentos de regulação da RSE, ao mesmo tempo em que demanda a verificação da conjuntura da aplicação e regulamentação da Responsabilidade Social no Brasil. Sob este panorama teórico, caminha-se na investigação da força normativa da RSE, correlacionando-se a vinculação entre os compromissos de responsabilidade social adotados pelas empresas e a sua exigibilidade pelos stakeholders, o que será realizado por meio da revisão biográfica e pelo desenvolvimento da pesquisa exploratória.
\end{abstract}

Palavras-chave: responsabilidade social da empresa; regulamentação; soft e hard law.

Abstract: The Company's Social Responsibility is the object of study in the most diverse areas of knowledge, with the common point of analysis of the company's role in view of the perspectives arising from globalization and the innovations of the 21 st century. The Law is responsible for examining CSR standardization initiatives, highlighting the normative force of non-state regulatory instruments and the adequacy and necessity of issuing general and abstract rules from the State. Therefore, it is imperative for the object of study to outline the main instruments of regulation of CSR, at the same time that it demands the verification of the situation of the application and regulation of Social Responsibility in Brazil. Under this theoretical framework, the investigation of the normative force of CSR is progressed, correlating the link between the social responsibility commitments adopted by companies and 
their demandability by stakeholders, which will be accomplished through the biographical review and the development of exploratory research.

Keywords: company social responsibility; regulation; soft and hard law.

\section{Para citar este artigo}

ABNT NBR 6023:2018

AGNOL, Phillippe Dall'; CARMONA, Paulo Afonso Cavichioli. A regulamentação da responsabilidade social empresarial: entre a ortodoxia e heteronomia normativa. Prisma Jurídico, São Paulo, v. 20, n. 2, p. 330-350, jul./dez. 2021. http://doi.org/10.5585/prismaj.v20n2.20253.

\section{Introdução}

A Responsabilidade Social da Empresa tem sido objeto de estudo por diversos ramos do conhecimento científico, existindo entre tais ramos a percepção comum de que a globalização tem promovido a ampliação da atuação das empresas e das relações entre empresários e demais segmentos da sociedade.

A partir desta constatação, torna-se necessário investigar de que maneira estão sendo regulados os comportamentos e padrões éticos das empresas e organizações face aos direitos humanos, ao meio ambiente e aos interesses da sociedade quanto a uma perspectiva holística, ou seja, de convergência de interesses entre as empresas e os stakeholders afetados pelo desempenho de atividade econômica e empresarial.

Realizadas tais análises, apresentam-se argumentos a fundamentar a compreensão das modalidades normativas da Responsabilidade Social, de maneira a racionalizar os padrões de regulação para alcançar a finalidade essencial da RSE, qual seja, harmonizar os interesses de todos os envolvidos na atividade econômica, garantindo-se a lucratividade das empresas e o bem-estar da sociedade.

Quanto ao aspecto metodológico, a abordagem do estudo se dará por meio da revisão bibliográfica dos marcos teóricos a respeito do tema, aliada ao levantamento de dados referentes ao objeto de estudo para o desenvolvimento da pesquisa exploratória.

\section{A regulamentação da responsabilidade social: entre as formas heterodoxas (soft law) e ortodoxas (hard law) de normatização}

Os escritos sobre a Responsabilidade Social da Empresa (RSE) têm em comum a conclusão do quão relativo é a apresentação conceitual da RSE, a depender do ramo científico 
de estudo e da perspectiva funcional instrumentalizada pela Responsabilidade Social voltada à atividade empresarial.

Por uma perspectiva jurídica, é possível investigar os elementos basilares da Responsabilidade Social da Empresa à luz do ordenamento jurídico nacional e internacional, destacando-se a construção teórico-normativo da RSE a partir da dicotomia entre hard e soft law.

Nestes contornos, observa-se que a definição de responsabilidade social tem demandado a sua compressão enquanto disposição voluntária ou obrigacional advinda da legislação, de maneira a identificar as fontes normativas e seus reflexos perante a padronização regulamentadora da responsabilidade social.

Ao examinar o estatuto jurídico da RSE na Colômbia, Acevedo-Guerrero et al. (2013, p. 303) destacam que,

Actualmente la discusión sobre lo que debe entenderse como RSE no es pacífica, mucho menos, sobre lo que debe implicar para las empresas ser socialmente responsables. Sin embargo, todas las construcciones teóricas se concentran frente al papel otorgado a los efectos que sobre la realidad se derivan del funcionamiento de las compañías, en un debate generado a raíz de los cada vez más acentuados casos de cuestionables prácticas corporativas, que naturalmente conducen a replantear la necesidad de controlar la actividad de las empresas, lo que se traduce en iniciativas orientadas a disciplinar el ejercicio empresarial; proposiciones que, según su naturaleza, pueden ubicarse o catalogarse como medidas duras o blandas de regulación, hard o soft law.

El soft law o derecho blando se entiende si se contrapone al término que le es inverso: el hard law o derecho duro que generalmente se utiliza para referenciar normas o regulaciones de carácter obligatorio, cuyas prescripciones son jurídicamente vinculantes y procesalmente exigibles ${ }^{1}$.

Portanto, as práticas de responsabilidade social adotadas pelas empresas, ou mesmo a ausência de tais comportamentos, especialmente quando em violação aos direitos humanos, ensejou a regulamentação da RSE a partir fontes formais brandas e de proposições regulamentadoras provenientes do Estado, com destaque para os mecanismos de compliance enquanto instrumento de fiscalização da SER face às violações dos direitos humanos, tal como argumentado por Nolan (2018, p. 76).

\footnotetext{
${ }^{1}$ Em tradução livre: Atualmente a discussão sobre o que deve ser entendido como RSE não é pacífica, muito menos sobre o que deveria significar para as empresas ser socialmente responsável. No entanto, todas as construções teóricas se concentram no papel dado aos efeitos que sobre a realidade decorrem do funcionamento das empresas, num debate gerado a partir dos casos cada vez mais acentuados de práticas empresariais questionáveis, que naturalmente levam a repensar a necessidade de controlar. a atividade das empresas, que se traduz em iniciativas que visam disciplinar a prática empresarial; proposições que, dependendo de sua natureza, podem ser identificadas ou classificadas como medidas "duras" ou "brandas"de regulação, hard ou soft law.

A Soft law ou direito brando é entendido se for contrário ao termo inverso: hard law ou direito "duro" que geralmente é usado para se referir a regras ou regulamentos obrigatórios, cujas prescrições são juridicamente vinculativas e processualmente exigiveis.
} 
Importante, neste momento, explanar os contornos conceituais do que vem a ser soft law e hard law. Em trabalho destinado a verificar a importância da soft law na evolução do direito internacional, Oliveira e Bertoldi (2012, p. 6.265) destacam que a doutrina vem revisitando as características estruturantes do direito, qual seja, "uma ordem jurídica, composta por normas obrigatórias e coercitivas, cuja identificação é realizada mediante critérios formais de validade". Argumentam as autoras que a

[...] a doutrina vem questionando, ampliando e modificando estas três características
básicas do direito. Terré, Bergel, Carbonnier refutam essa visão reduzida do direito
como um simples conjunto de regras, afirmando que o direito é mais amplo que a
regra, posto que o direito é igualmente costume, pratica, jurisprudencia, etc. Quanto
ao caratér obrigatório, Molfessis destaca que ao se considerar o critério obrigatório
como essencial ao direito ignora-se as demais manifestaçães possiveis do direito. Por
fim, a juridicidade não pode se subordinar à sanção, uma vez que existem regas em
direito internacional e constitucional que mesmo sem impor sanção continuam sendo
regras jurídicas. Nesse sentido assinala Virally “uma norma não é jurídica porque ela
é capaz de impor sanção. Ela sanciona porque ela é jurídica". Entendendo que o direito
é composto não somente por um conjunto de normas jurídicas obrigatórias e capazes
de impor sanção, passamos a análise do direito internacional e dos instrumentos de
soft law.

Adotando a roupagem de direito proposta pelas autoras, é possível concluir que a soft law expande a construção jurídica da norma, elevando em grau de importância normativa elementos historicamente secundários na hermenêutica jurídica. Na mesma medida, desconstrói a redução do direito ao binômio obrigatoriedade-sanção, agregando à juridicidade elementos modernos e provenientes das inovações advindas da globalização e das mudanças comportamentais do século XXI.

Delineadas as principais características da soft law, passa-se à análise das elementares da construção teórica da denominada hard law. Inicialmente, sobreleva destacar a problemática na definição e conceituação precisa do que vem a ser hard law, também denominada como direito cogente.

Shaffer e Pollack (2009, p. 706) ressaltam o desencontro de conceitos na literatura jurídica, destacando, entretanto, que várias das correntes teóricas recorrem à perspectiva binária obrigatoriedade/não-obrigatoriedade como fator determinante para a distinção entre o direito brando e o direito cogente.

Por outro lado, existem perspectivas com contextualizam o direito cogente à normatividade, à exigibilidade e à possibilidade de judicialização (HARTLAPP; HOFMANN, 2020, p. 4), ao passo que Abbott e Snidal (2000, p. 421) esclarecem que o termo hard law é usado como referência às obrigações legalmente definidas e que são objeto de delegação à autoridade que interpretará e aplicará a norma. Neste raciocínio, 


\begin{abstract}
[t]he term hard law as used in this special issue refers to legally binding obligations that are precise (or can be made precise through adjudication or the issuance of detailed regulations) and that delegate authority for interpreting and implementing the law. Although hard law is not the typical international legal arrangement, a close look at this institutional form provides a baseline for understanding the benefits and costs of all types of legalization. By using hard law to order their relations, international actors reduce transactions costs, strengthen the credibility of their commitments, expand their available political strategies, and resolve problems of incomplete contracting. Doing so, however, also entails significant costs: hard law restricts actors' behavior and even their sovereignty ${ }^{2}$.
\end{abstract}

À luz destas considerações, é possível argumentar que o direito cogente tem por fundamento uma base normativa, a qual é vinculante em razão da sua normatividade e pode ser judicialmente exigível a sua observância. Por outras palavras, existe uma correspondência entre normatividade, vinculação e enforcement da obrigação prevista em abstrato (SAURUGGER; TERPAN, 2020, p. 4).

Uma vez estabelecidos os parâmetros normativos do direito, necessária é a verificação destes preceitos aplicados à Responsabilidade Social da Empresa, com ênfase no debate quanto à voluntariedade ou obrigatoriedade da observância da RSE pelas empresas.

Por meio do estudo denominado Governance, International Law \& Corporate Social Responsibility, a Organização Internacional do Trabalho (OIT) realizou detalhado exame quanto às características normativas da Responsabilidade Social Corporativa (sinônimo de RSE), bem como identificou a proliferação das iniciativas de regulação e autorregulação da responsabilidade social realizadas pelos agentes privados (CLAVET, 2008, p. 34).

Nesse estudo, verificou-se, tal como na compreensão de hard e soft law, a divisão da doutrina quanto à necessidade de normatização da RSC. Numa primeira corrente, compreendese que a RSE está diretamente ligada a uma espécie de norma moderada (soft law), com limitado alcance obrigacional quanto aos fatos materiais (naturalísticos) propriamente ditos. Tal conclusão está embasada no fato de que a RSC não é regulamentada pelo Direito, e, ante à ausência de normatividade, as empresas não estariam obrigadas a se comprometer com as diretrizes da RSE, as quais seriam, por consequências, indicativas e não compulsórias.

Por outro lado, existe entendimento no sentido de que a Responsabilidade Social Empresarial é mais apropriada do que os instrumentos normativos tradicionais, considerando-

\footnotetext{
${ }^{2} \mathrm{Em}$ tradução livre: O termo hard law, utlizado neste contexto refere-se a obrigações juridicamente vinculativas que são precisas (ou podem ser tornadas precisas por meio de adjudicação ou emissão de regulamentos detalhados) e que delegam autoridade para interpretar e implementar a lei. Embora a hard law não seja o arranjo jurídico internacional típico, um exame mais atento dessa forma institucional fornece uma base para a compreensão dos benefícios e custos de todos os tipos de legalização. Ao usar a hard law para ordenar suas relações, os atores internacionais reduzem os custos de transação, fortalecem a credibilidade de seus compromissos, expandem suas estratégias políticas disponíveis e resolvem problemas de incompletude contratual. Fazer isso, no entanto, também acarreta custos significativos: a hard law restringe o comportamento dos atores e até mesmo sua soberania.
} 
se o panorama factual proporcionado pela globalização econômica e pelos desafios de responsabilidade ambiental no desempenho da atividade empresarial (PASCHKE, 2019, p. 01).

Nesta perspectiva, a RSC poderá fornecer instrumentos flexíveis para atender os stakeholders de forma adequada e não concretizada pelos modelos normativos tradicionais, de maneira a se vislumbrar uma nova categoria de normas, quais sejam, as normas sociais, tal como argumentado por Ruggie (2017, p. 13).

Por fim, uma terceira perspectiva entende que a RSE e os instrumentos normativos tradicionais não são excludentes, pelo contrário, são complementares na efetivação dos direitos básicos e na proteção dos interesses afetadas pelo desempenho das atividades econômicas e empresariais.

Uma vez identificadas as perspectivas teóricas quanto à eficácia normativa da RSC, observa-se a existência de duas estruturas regulatórias básicas, com pressupostos conceituais distintos e promovidas por agentes reguladores diversos.

A primeira advém das iniciativas de regulação privada realizadas por empresários, onde se debate a efetividade dos instrumentos regulatórios privados, bem como a necessidade, ou não, de harmonização destes regulamentos e iniciativas com o propósito der se dar segurança jurídica a todos os afetados pelas relações jurídicas mantidas com as empresas. Tal perspectiva baseia-se, portanto, na denominada soft law.

A segunda estrutura regulatória é embasada na ortodoxa normatização estatal e tem como fundamento a edição de atos normativos dotados de eficácia abstrata, geral e de observância obrigatória, características estas ligadas à regulamentação denominada de hard law.

Todas estas ideias são colocadas como ponto de partida para o estudo das iniciativas de regulação da RSE, em especial para o seu avanço nos últimos anos. Para muito além de uma análise conceitual, observa-se a existência de perspectivas práticas e teóricas quanto à compressão da RSE e dos atores que a envolvem, num panorama de debate e estudo quanto às modalidades de regulamentação da responsabilidade social.

\section{Os instrumentos de regulação da RSE}

Uma vez identificado que a regulação da RSE pode ser oriunda de normas de origem estatal e não estatal, passa-se à verificação dos principais instrumentos reguladores da responsabilidade social. 
No âmbito da Responsabilidade Social Corporativa imperam as denominadas normas voluntárias e de consenso, as quais representam a padronização e regulação técnica necessária para o desenvolvimento das atividades empresariais nos mais diversos setores e segmentos da economia. E é por meio destas normas técnicas de consenso que se estabelecem os principais mecanismos reguladores da SER (GONÇALVES, 2020, p. 529).

Inicialmente, destaca-se a utilização de certificações como modelo de padronização e observância da responsabilidade social. Entre as diversas certificações, algumas são consideraras fundamentais à RSE.

A primeira é a Social Accountability Certification SA 8000, que é uma norma de certificação internacional que estabelece padrões e impactos sociais voltados à relação de trabalho, ao mesmo tempo em que incentiva as organizações a manter práticas socialmente responsáveis no ambiente de trabalho. A certificação SA 8000 aborda a padronização de questões como o trabalho escravo e infantil; saúde e segurança do trabalho; liberdade de associação e negociação coletiva; discriminação; práticas disciplinares; jornada de trabalho; remuneração e sistemas de gestão.

A SA 8000 também incorpora entre os seus elementos de padronização acordos internacionais existentes, incluindo as convenções da Organização Internacional do Trabalho, a Declaração Universal dos Direitos Humanos e a Convenção das Nações Unidas sobre os Direitos da Criança.

Nas palavras de Kraemer (2003, p. 13), a "SA 8000 constitui um instrumento de informação extremamente importante para o consumidor globalizado, pois, atualmente, os fatores determinantes da sua escolha vão além de preço e qualidade". Para muito além dos padrões tradicionais de requisitos de escolha de produtos, as "pessoas necessitam saber como o produto ou serviço que estão adquirindo foi produzido, repudiando imediatamente aqueles que agregam procedimentos como, por exemplo, o trabalho infantil” (KRAEMER, 2003, p. 13).

Outro relevante regramento da RSE é a ISO 26000, conhecida como a primeira norma internacional de responsabilidade social. De início, é importante mencionar que a norma em questão não é uma modalidade de certificação, mas um conjunto de princípios e orientações de boas práticas e de sustentabilidade que tem por finalidade promover a inovação social, ou seja, resolver problemas sociais de maneira mais efetiva, eficiente e sustentável (HARDIANA, 2020, p. 41).

No âmbito da Responsabilidade Social, tem-se como extreme de dúvidas que esta é a norma de maior referência no mundo, com a particularidade de ter sido editada sob a liderança de um brasileiro, consoante interessante estudo sobre o tema: 
A ISO 26000 foi concebida para ser a primeira norma internacional de Responsabilidade Social Empresarial. Ela começou a ser desenvolvida em 2005 e sua versão final foi publicada no final 2010. O documento tem como objetivo traçar diretrizes para ajudar empresas de diferentes portes, origens e localidades na implantação e desenvolvimento de políticas baseadas na sustentabilidade. Foi construída com a participação de diversos setores da sociedade, em todo mundo, e liderada por um brasileiro: o engenheiro Jorge Cajazeira, gerente corporativo de competitividade da Suzano Papel e Celulose, responsável pelo Grupo de Trabalho e Responsabilidade Social da ISO (International Organization for Standardization). Sua criação se deu durante uma reunião do Comitê de Política de Consumidores da ISO (Copolco), em 2001, que se cogitou, pela primeira vez, a criação de uma norma global de Responsabilidade Social Corporativa. No entanto, o documento só passou a ser discutido em 2005. Desde então, uma série de encontros do comitê organizador já ocorreram em diversas partes do mundo. A norma internacional tem a proposta de servir como um importante norte para as corporações e não como uma certificadora (DANTAS; SIQUEIRA; NOBRE; GIESTA; SPERS, 2016, p. 126).

Neste mesmo contexto, é importante destacar ainda que

[a] ISO 26000 foi elaborada pelo ISO/TMB Working Group on Social Responsibility (ISO/TMB WG SR) por meio de um processo multi-partite que envolveu especialistas de mais de 90 países e 40 organizações internacionais ou com ampla atuação regional envolvidas em diferentes aspectos da responsabilidade social. Esses especialistas vieram de seis diferentes grupos de partes interessadas: consumidores; governo; indústria; trabalhadores; organizações não governamentais (ONG); serviços, suporte, pesquisa, academia e outros. Além disso, buscou-se um equilíbrio entre países em desenvolvimento e desenvolvidos, assim como um equilíbrio entre gêneros na elaboração dos grupos (ABNT. ISO. ABNT NBR ISO 26000, 2010).

Portanto, depreende-se que a ISO 26000 é resultado do trabalhado multifacetado e de ampla representação, por meio da qual foram traçadas as seguintes diretrizes e princípios para o cumprimento da responsabilidade social: responsabilidade; transparência; comportamento ético; consideração pelas partes interessadas; legalidade; normas internacionais e Direitos Humanos. Além da enunciação de princípios, os temas centrais do documento envolvem as áreas de Direitos Humanos; Práticas de Trabalho; Meio Ambiente; Práticas Leais de Operação; Combate à Corrupção e Propina; Consumidores e Desenvolvimento, aliado à participação comunitária (MATTOS, 2020, p. 40).

Denota-se que a norma é resultado da participação de diversos países, organizações e especialistas, consolidando-se em diretrizes, princípios e orientações voltadas aos temas fundamentais da responsabilidade social, os quais podem ser aplicados a todas as organizações dos setores privado, público e às entidades sem fins lucrativos, amplamente denominadas como entidade pertencentes ao Terceiro Setor.

Além das normas e certificações acima indicadas, é de grande relevância para a regulação da responsabilidade social o programa da Organização das Nações Unidas que tem como objetivo mobilizar a comunidade empresarial na promoção de valores fundamentais afeitos às áreas de direitos humanos, relações de trabalho e meio ambiente, o qual recebeu a 
denominação de Global Compact, e que é, atualmente, a "maior iniciativa de sustentabilidade corporativa do mundo" (PACOBELLO; BITTENCOURT; BENEDICTO; NEVES, 2021, p. 72675).

Conforme informações do Instituto Ethos (2002), o programa foi desenvolvido pelo secretário-geral, Kofi Annan, e tem como fundamento o fato de que as empresas devem contribuir para o desenvolvimento de uma estrutura socioambiental consistente, em mercados livres e abertos, assegurando que todos desfrutem dos benefícios da nova economia global.

O programa propõe um pacto global para atuação das empresas com fundamento em quatro grupos de princípios, que foram divididos em 10 subprincípios, e que delineiam de forma ampla a responsabilidade e o dever de observância e vigilância pelas empresas.

O primeiro grupo são princípios voltados à proteção dos Direitos Humanos, devendo a empresa respeitar, proteger e impedir violações de Direitos Humanos. O segundo grupo é formado por princípios de Direitos do Trabalho, sendo incumbência das empresas apoiar a liberdade de associação no trabalho, abolindo o trabalho forçado e o trabalho infantil, além de eliminar a discriminação no ambiente de trabalho. O terceiro grupo é o de princípios de Proteção Ambiental, competindo às empresas apoiar uma abordagem preventiva aos desafios ambientais, promovendo a responsabilidade ambiental e encorajando tecnologias que não agridam o meio ambiente. Finalizando, tem-se o princípio contra a corrupção, que determina a todas as organizações a constante luta e vigilância contra toda forma de corrupção.

Além dos exemplos acima indicados de normas brandas (soft power) de regulação da RSE, não se pode deixar de mencionar a relevância do código de ética (conduta) e os relatórios de responsabilidade.

Os códigos de ética são documentos editados por empresas e organizações (públicas ou privadas) com a finalidade de delimitar os padrões de comportamento dos colaboradores no ambiente interno e externo, de maneira a esclarecer o comportamento mínimo esperado nas relações empresariais e jurídicas estabelecidas entre empresa e os stakeholders.

Por outro lado, o Relatório de Sustentabilidade (Responsabilidade Social ou apenas Relatório Ambiental), é o documento utilizado na divulgação e prestação de contas do exercício da responsabilidade social por parte das organizações aos stakeholders. Nas palavras de Oliveira, Ferreira e Lima (2015, p. 165-166): 
[u]ma das formas de que as organizações dispõem para divulgar junto dos seus stakeholders, o seu desempenho socialmente responsável, é através da elaboração e publicação anual de um Relatório de Sustentabilidade (Responsabilidade Social ou apenas Relatório Ambiental), muitas vezes independente do Relatório e Contas, e onde se faz a descrição do desempenho nas vertentes social, ambiental e económica (HELENO, 2008). Elaborar relatórios de sustentabilidade consiste na prática de medir, divulgar e prestar contas, às várias partes interessadas, sobre o desempenho da organização, visando atingir o objetivo do desenvolvimento sustentável. A expressão 'elaboração de relatórios de sustentabilidade' é abrangente, e considerada sinónima de outros termos e expressões utilizados para descrever a comunicação dos impactos económicos, ambientais e sociais (por ex: triple bottom line, relatórios de responsabilidade corporativa etc.). Algumas iniciativas com maior importância como a Global Reporting Initiative (GRI) constituem uma boa referência, oferecendo um guia de diretrizes para a elaboração de relatórios de sustentabilidade.

Estes são, de forma exemplificativa, alguns dos principais instrumentos de regulação da RSE. O ponto comum entre eles é o pressuposto de que a responsabilidade social deve ser alcançada por meio do respeito e efetivação do mais amplo aspecto dos Direitos Humanos e da preservação do meio ambiente, sendo responsabilidade das empresas e organizações públicas e privadas laborarem na consecução de objetivos globalmente aceitos e de observância obrigatória.

Numa outra perspectiva, é possível encontrar regramentos sobre responsabilidade social por meio da edição de leis e regulamentos provenientes do Estado no exercício da função regulamentadora. Interessante notar que a maior parte da legislação voltada à regulação da RSE tem como ponto de partida o regramento do balanço social (HAYASHI, 2020, p. 25).

Dantas conceitua o balanço social como sendo:

[...] um demonstrativo que evidencia de forma quantitativa e qualitativa os investimentos e projetos das organizações que visam o bem estar da sociedade, como também, a redução dos possíveis danos ambientais resultantes de suas atividades, ou seja, tem o potencial de fomentar o lado social e humano da entidade. É um instrumento de informação da empresa para a sociedade, uma ferramenta que agrega valor aos negócios, pois através do balanço, pode-se criar um vínculo de credibilidade com clientes, colaboradores, investidores e demais usuários (DANTAS, 2011, p. 15).

Do conceito apresentado é possível inferir-se que o balanço social é um instrumento que viabiliza a prestação de contas à sociedade (e aos stakeholders) por meio de relatórios não financeiros que avaliam aspectos sociais, ambientais e econômico para alcançar uma dupla função: ser um instrumento de gestão sustentável e um meio de comunicação entre a organização e seus stakeholders (MACHADO; SILVA, 2020, p. 4 e 5).

Embasados na premissa de que a empresa tem obrigações para além do seu campo de atuação, ou melhor, que as empresas devem ser responsivas à sociedade (OLIVEIRA; LEITE, 2014, p. 251), com a observância de boas práticas e implementação de projetos e programas com metas voltadas a alcançar resultados na preservação do meio ambiente e submissão de suas 
atividades ao império dos Direitos Humanos, foram editadas diversas leis que regulamentaram os elementos essenciais do balanço social.

Num breve panorama histórico sobre a legislação reguladora do balanço social, exsurgese que as décadas de 1960 e 1970 foram fundamentais no desenvolvimento da regulação da RSE. Tal afirmação é possível a partir da compreensão de que

\begin{abstract}
[n]os Estados Unidos, país pioneiro no desenvolvimento do Balanço Social, o tema começou a ser abordado principalmente por causa da guerra do Vietnã, em que a maioria da população americana era contra esse conflito e principalmente questionava os seus métodos. Em virtude disso, as pessoas passaram a boicotar as empresas ligadas de alguma forma à Guerra do Vietnã, principalmente as evolvidas com fabricação de armas. Consequentemente, as empresas americanas preocupadas em recuperar sua imagem e prestígio social abalados pela Guerra do Vietnã, resolveram prestar informações à sociedade através de relatórios sócio-econômicos, procurando divulgar as informações das relações sociais da empresa. Ainda segundo Tinoco (2001), a Alemanha em 1971, por intermédio da empresa STEAG, produziu uma espécie de relatório social que continha apenas um balanço de suas atividades sociais. Mas foi na França em 1972 que surgiu o primeiro Balanço Social propriamente dito, elaborado pela empresa SINGER. E em 1977, entrou em vigor a Lei $\mathrm{n}^{\circ} 77.769$, de 12 de julho de 1977, que obrigava as empresas com mais de trezentos funcionários elaborarem seu Balanço Social. De acordo com Santos (2009), a Holanda destacou-se na evolução do Balanço Social, pois foi o primeiro país a ter publicado os relatórios sociais com objetivo de informar seus funcionários. Na Espanha, apesar de não haver obrigatoriedade de elaboração e publicação do Balanço Social, há uma maior conscientização das empresas, que entendem que devem ser mais transparentes e fornecer informações não só aos acionistas, mas também aos empregados, aos sindicatos, entidades sem fins lucrativos, e à sociedade; por essa razão, elaboram seu Balanço Social (SANTOS, 2009). Em Portugal, a primeira experiência relacionada ao Balanço Social foi em 1977, com estudos relacionados ao tema nas 100 maiores empresas do país. Segundo Tinoco (2001), no início da década de 80, cerca de 20 empresas elaboraram seu Balanço Social influenciados pelos franceses. Em 1985, graças aos esforços do grupo parlamentar ex-Asdi, culminou a criação da Lei $n^{\circ} 141 / 85$ que obrigava as empresas públicas e as empresas que tinham 500 ou mais funcionários a publicarem o Balanço Social. Atualmente, em Portugal, de acordo com o Decreto-lei $\mathrm{n}^{\circ}$ 9/92, o Balanço Social deve ser elaborado e entregue por todas as empresas com mais de 100 funcionários (MATTOS; SILVA; ZATTA, 2011, p. 2021).
\end{abstract}

Avançando no contexto histórico, em interessante compilamento doutrinário, Almeida et al. (2012, p. 12) traça os principais eventos que propiciaram a regulamentação estatal do balanço social, conforme se depreende do Quadro 1: 
QUADRO 1 - Síntese histórica da inserção do Balanço Social

\begin{tabular}{|c|c|c|}
\hline País & Datas & Fundamentação \\
\hline EUA e Europa & Década 60 & $\begin{array}{l}\text { Ocorrência das primeiras experiências na elaboração do Balanço } \\
\text { Social. }\end{array}$ \\
\hline França & Década 70 & $\begin{array}{l}\text { O Institut de I'Entrepise em colaboração com uma equipe de } \\
\text { investigadores concede, inicialmente o Balanço Social como um } \\
\text { método global de investigação social para o diagnóstico da "saúde" } \\
\text { social e para a planificação estratégica do futuro das organizações, } \\
\text { originando o Relatório Suldreau. }\end{array}$ \\
\hline Inglaterra & Década 70 & $\begin{array}{l}\text { Diversas entidades de classe, pesquisadores e professores pressionam } \\
\text { as organizações para a divulgação de informações socioeconômicas, } \\
\text { mais completas, principalmente para os trabalhadores do que as } \\
\text { contidas nos relatórios contábeis. Nessa década surge também forte } \\
\text { discussão sobre a responsabilidade } \\
\text { social. }\end{array}$ \\
\hline França & Década 1972 & $\begin{array}{l}\text { A empresa SINGER - Industrie et Commerce elabora e divulga o } \\
\text { que se pode chamar de primeiro Balanço Social (Bilan Social) das } \\
\text { empresas. }\end{array}$ \\
\hline Portugal & Década 1974 & $\begin{array}{l}\text { Transformações políticas e sociais relativas a conflitos sobre } \\
\text { reivindicações salariais no meio rural, conhecida como a Revolução } \\
\text { dos Cravos. }\end{array}$ \\
\hline Inglaterra & Década 1975 & $\begin{array}{l}\text { A Accounting Standards Steering Commitee (ASSC) publica The } \\
\text { Corporate Report, que ressalta a importância de reunir informações } \\
\text { econômicas e sociais em um relatório capaz de informar investidores } \\
\text { e assalariados. }\end{array}$ \\
\hline França & Década 1977 & $\begin{array}{l}\text { Primeiro país do mundo a ter uma lei (Lei n }{ }^{\circ} 77.769 \text { de } 12 \text { de julho } \\
\text { 1977) que obriga as empresas que tenham mais de } 300 \text { funcionários } \\
\text { a elaborar e publicar o Balanço Social. }\end{array}$ \\
\hline Alemanha & Década 80 & $\begin{array}{l}\text { Em consonância com banqueiros e professores universitários, o } \\
\text { Instituto Battelle, recomenda às empresas a elaboração de relatórios } \\
\text { socioeconômicos, apesar de não haver legislação específica sobre o } \\
\text { Balanço Social. }\end{array}$ \\
\hline Portugal & Década 1985 & $\begin{array}{l}\text { A Lei } \mathrm{n}^{\circ} 141 \text { introduz os primeiros formatos do Balanço Social, } \\
\text { determinando a elaboração de um documento sobre o conjunto de } \\
\text { informações em relação ao aspecto social das entidades com mais de } \\
100 \text { funcionários. }\end{array}$ \\
\hline Holanda & Década 90 & $\begin{array}{l}\text { Os Sindicatos do Comércio e Indústria sugerem a divulgação de Social } \\
\text { Jarverslag (Relatórios Sociais) com enfoque nas informações sobre as } \\
\text { condições de trabalho e estatísticas sobre o emprego (DE } \\
\text { LUCA, 1998). }\end{array}$ \\
\hline Suécia & Década 90 & $\begin{array}{l}\text { Os Sindicatos do Comércio e Indústria recomendam a elaboração do } \\
\text { Balanço Social com ênfase nas informações para os empregados (DE } \\
\text { LUCA, 1998). }\end{array}$ \\
\hline Portugal & Década 1992 & $\begin{array}{l}\text { O Decreto - lei } n^{\circ} \text { 9/92 leva o Balanço Social a dar maior ênfase às } \\
\text { ações sociais da empresa destinadas à melhoria de vida da } \\
\text { comunidade. O Balanço Social divulgado enfatiza o nível de emprego, } \\
\text { os custos com pessoal, higiene e segurança, formação } \\
\text { profissional e proteção social complementar. }\end{array}$ \\
\hline Bélgica & Década 1996 & $\begin{array}{l}\text { Institui o Balanço Social baseado e fundamentado no princípio } \\
\text { contábil da perenidade das entidades, o que lhe confere a condição de } \\
\text { permanência e longevidade, sendo uma elaboração obrigatória a } \\
\text { todas as empresas e devendo ser publicado anualmente em conjunto } \\
\text { com as demais demonstrações contábeis. }\end{array}$ \\
\hline
\end{tabular}

Fonte: Almeida, apud Reis, Medereiros (2009, p. 44-47); Tinoco (2001, p. 125). 
Do quadro acima delineado, é possível verificar que vários países da Europa têm regulamentado o balanço social como instrumento de aferição da responsabilidade social das empresas. Destas regulações, representativas da hard law, é que se originou o debate quanto à necessidade de edição de lei para regulação da RSE ou a utilização dos instrumentos voluntários para padronização e normatização da responsabilidade social das empresas, acima referenciado como soft law.

O Brasil não ficou alheio ao debate, conforme se verificará no seguinte tópico deste ensaio.

\section{A regulamentação da RSE no Brasil}

$\mathrm{Na}$ linha do que foi destacado, existe grande debate quanto à necessidade, ou não, de regulação da Responsabilidade Social Corporativa, especialmente quanto à elaboração e publicação do balanço social, uma vez que inexiste no Brasil uma norma nacional que estabeleça regras e diretrizes para a elaboração deste instrumento contábil (LEITE; SILVA; SANTOS, 2018, p. 6).

Conforme as lições de Oliveira (2013, p. 15), para os defensores da regulação, o balanço social é o instrumento necessário para permitir o acesso pelos stakeholders quanto às informações negligenciadas pelas empresas ou auditorias especializadas. Outro argumento utilizado é que os atuais balanços sociais divulgados no Brasil não possuem o nível de qualidade satisfatório para atender as demandas de informação dos stakeholders.

Por outro lado, existe o entendimento de que a iniciativa privada não poderia ser obrigada a arcar com os custos de elaboração e publicação do balanço social, uma vez que esta seria uma obrigação imposta ao setor privado sem qualquer contraprestação por parte do Poder Público (RIBEIRO; PINTO, 2004, p. 25).

Além disso, os defensores da voluntariedade do balanço social para as empresas privadas argumentam que, se necessária a regulação e obrigatoriedade da elaboração e publicação desta peça informativa, deve-se começar a impor tal obrigação às empresas estatais e ao Estado, na linha do que foi argumentado por Souza (1997, p. 02): 
Todas as empresas estatais deveriam tornar transparente a dimensão social. $\mathrm{O}$ fato de serem públicas não garante automaticamente uma preocupação com o tema. Ao longo da história, já foi percebido que, muitas vezes, essas instituições deturpam objetivos de caráter social em prol de interesses privados. Tal ideia deve atingir principalmente os governos municipais. Por natureza, as prefeituras são sociais, mas, geralmente, privatizadas em suas práticas e desligadas do interesse maior, da coletividade. Não custa publicar um balanço social adaptado às prefeituras. Existe, portanto, um campo aberto para a convergência de projetos relativos ao balanço social, que devem ser desenvolvidos o quanto antes. Assim, haverá uma conexão com os inúmeros problemas sociais que o Estado, sozinho, tem se revelado incapaz de resolver. A iniciativa privada, muitas vezes, não se sente comprometida com o mundo em que vive e trabalha.

Não obstante o debate contrário ou favorável à regulação da RSE, o fato é que existe no Brasil a compressão sobre a possibilidade de dupla regulamentação da responsabilidade social, ou seja, tanto na forma da hard law como na soft Law.

Por meio das normas brandas, as empresas e organizações brasileiras têm criado diversos mecanismos para promoção e execução da responsabilidade social corporativa. Entre estes mecanismos, alguns têm recebido destaque nacional e internacional.

O primeiro deles é o Índice de Sustentabilidade Empresarial da Bolsa de Valores do Estado de São Paulo (ISE/BOVESPA), que tem como propósito identificar e mensurar a atuação das empresas e o grau de compromisso assumido quanto ao comportamento socialmente responsável, provendo informações aos investidores e acionistas que direcionam investimentos em empresas comprometidas com a responsabilidade social. Sousa e Cortês (2006, p. 11) destacam que

\begin{abstract}
[a] idea do índice, segundo seus idealizadores é o de servir como mais um instrumento no equacionamento dos desafios impostos na busca do desenvolvimento sustentável, por constituir ferramenta que poderá ajudar as empresas a assegurarem menos desperdícios e a proteção dos direitos socioambientais, ao mesmo tempo em que geram mais valor, e conseqüentemente mais riqueza e mais lucro. Pode servir também para sinalizar para as empresas e grupos empresariais quais são os prováveis caminhos para a construção de uma economia mais eficiente sob o ponto de vista do uso dos recursos naturais e menos impactante sobre o meio ambiente e sociedade, potencializando o valor dos produtos e serviços por unidade de recurso ambiental aplicado.
\end{abstract}

Outra norma relevante na regulamentação por meio da soft law no Brasil é a ABNT NBR 16001. Tal instrumento tem como característica implementar um sistema de gestão de responsabilidade social passível de certificação pela ABNT, desde que observados os compromissos essenciais de promoção da cidadania, do desenvolvimento sustentável e de transparência das atividades da empresa.

Conforme informações da ABNT (ABNT NBR 16001), a norma estabelece os requisitos mínimos relativos a um sistema de gestão eficaz da responsabilidade social, permitindo que a 
organização formule e implemente uma política com objetivos que levem em conta seus compromissos com:

a) a responsabilização (accoutability) a transparência;

b) o comportamento ético;

c) o respeito pelos interesses das partes interessadas;

d) o atendimento aos requisitos legais e outros requisitos subscritos pela organização;

e) o respeito às normas internacionais de comportamento;

f) o respeito aos direitos humanos;

g) a promoção do desenvolvimento sustentável.

No mesmo sentido, é possível extrair da NBR 16001 que a norma é passível de integração com outros requisitos de gestão e estabelece critérios que se aplicam a qualquer modelo e porte de organização que tenha a pretensão de implantar, manter e aprimorar um sistema de gestão da RSE; assegurar-se de sua conformidade com a legislação aplicável e com a sua política da RSC; apoiar o engajamento das partes interessadas; demonstrar conformidade com a norma seja realizando auto avaliação e emitindo autodeclaração da conformidade, seja buscando confirmação de sua conformidade por partes interessadas ou partes externas à organização; seja buscando a certificação do seu sistema de gestão da responsabilidade social por uma organização externa.

Sob essa perspectiva, cumpre apontar a relevância dos indicadores Ethos para negócios sustentáveis e responsáveis. Em consonância com o Instituto responsável por sua formulação,

[os] Indicadores Ethos são uma ferramenta de gestão que visa apoiar as empresas na incorporação da sustentabilidade e da responsabilidade social empresarial (RSE) em suas estratégias de negócio, de modo que esse venha a ser sustentável e responsável. A ferramenta é composta por um questionário que permite o autodiagnóstico da gestão da empresa e um sistema de preenchimento on-line que possibilita a obtenção de relatórios, por meio dos quais é possível fazer o planejamento e a gestão de metas para o avanço da gestão na temática da RSE/Sustentabilidade. Assista o vídeo sobre os Indicadores Ethos, clicando aqui.

A atual geração dos Indicadores Ethos, que será continuamente aprimorada, apresenta uma nova abordagem para a gestão das empresas e procura integrar os princípios e comportamentos da RSE com os objetivos para a sustentabilidade, baseando-se num conceito de negócios sustentáveis e responsáveis ainda em desenvolvimento. Além de ter maior integração com as diretrizes de relatórios de sustentabilidade da Global Reporting Initiative (GRI), com a Norma de Responsabilidade Social ABNT NBR ISO 26000, CDP, e outras iniciativas (INSTITUTO ETHOS, 2002).

Trata-se, portanto, de um mecanismo de avaliação e mensuração do exercício da responsabilidade social e da sustentabilidade pela empresa avaliada, de forma a auxiliar na 
elaboração de diagnósticos, projetos e fixação de metas no desempenho de atividade socialmente responsáveis.

Por fim, cumpre mencionar que o Brasil tem demonstrado algumas inciativas e tentativas de regulação da Responsabilidade Social Corporativa por meio da edição de regulações provenientes do Estado ou de entes que desempenham funções estatais. Em conformidade com os escritos de Carvalho e Siqueira (2009, p. 28), até o ano de 2009,

[f]oram identificadas dez regulamentações brasileiras que fornecem padrões para o desenvolvimento do Balanço Social: no âmbito das normas de contabilidade, a NBCT 15 e a Resolução CRC-RJ 292/2001; na esfera federal, o Projeto de Lei 32/1999 (em substituição ao Projeto de Lei 3.166/1997 arquivado em 02/02/1999) e o Projeto de Lei 1.305/2003; na esfera estadual, a Lei 11.440/2000 do Rio Grande do Sul, a Lei 7.987/2002 do estado do Mato Grosso, e a Lei 2.843/2003 do estado do Amazonas; e na esfera municipal, a Lei 7.672/1998 de Santo André (SP), a Lei 8.118/1998 de Porto Alegre (RS) alterada pela Lei 8197/1998, a Lei 9.536/2004 de Londrina (PR).

Das iniciativas normativas acima indicadas, destaca-se o projeto de lei $\mathrm{n}^{\circ} 3.166 / 1997$, posteriormente substituído pelo PL no 32/1999. Nestas propostas legislativas, tornava-se obrigatória a elaboração do Balanço Social pelas empresas privadas que tivessem cem empregados ou mais no ano anterior à sua elaboração, bem como as empresas públicas, sociedades de economia mista, empresas permissionárias e concessionárias de serviços públicos em todos os níveis da administração pública, independentemente do número de empregados.

Ademais, delineavam-se os principais elementos e informações que obrigatoriamente iriam compor o balanço social, fixando prazo e sanções ao não cumprimento da obrigação legalmente imposta.

Entretanto, o referido projeto foi arquivado pela Câmara dos Deputados. Segundo notícia publicada pela casa legislativa,

\footnotetext{
[o]s deputados concordaram com o relator, deputado Renato Molling (PP-RS), que foi contra o projeto. Para ele, "a sociedade, as entidades civis e as empresas têm dado demonstração clara e inequívoca de que os mecanismos sociais e empresariais já existentes são suficientes para garantir a evolução firme nas questões da responsabilidade social e da sustentabilidade."

$\mathrm{Na}$ opinião do relator, a elaboração do balanço social não deve ser impositiva, e sim uma escolha das empresas. A obrigatoriedade, diz ele, "desfigura o objetivo primordial do balanço, que é o de desenvolver a responsabilidade social como interesse da empresa.” (BRASIL. CÂMARA DOS DEPUTADOS, 2010).
}

Verifica-se, portanto, que no Brasil o debate quanto à forma de regulamentação da Responsabilidade Social da Empresa está em aberto. Nota-se a existência da regulação voluntária, ao mesmo tempo em que se destacam as tentativas de normatização por meio de lei, as quais, no entanto, ainda guardam resistência no parlamento, no empresariado e nas organizações que terão suas atividades reguladas pelo ato normativo estatal. 


\section{Conclusão}

$\mathrm{O}$ artigo buscou investigar e descrever as duas principais modalidades de regulação utilizadas no âmbito da Responsabilidade Social da Empresa. Neste aspecto, desenvolveu-se a linha argumentativa de que é plenamente possível a utilização da regulação voluntária e privada (soft law) e da regulamentação por meio da edição de ato normativo estatal (hard law), conforme delineado por meio de experiências normativas descritas no texto.

Após a investigação do contexto histórico e do panorama internacional das iniciativas de regulação da RSC, verificou-se os principais instrumentos utilizados para a padronização e normatização da Responsabilidade Social da Empresa, com a indicação das características aplicadas ao objeto de estudo do presente artigo.

Feitas estas considerações, foi possível concluir que a Responsabilidade Social das Empresas comporta uma gama de múltipla regulação. Seja com fundamento nas experiências internacionais ou mesmo sob a perspectiva do cenário nacional, o que se observa é a necessária adequação e atualização das normas e parâmetros às peculiaridades da RSE, em especial, da sua amplitude científica e setorial.

Tamanha é a peculiaridade da RSC, que é possível pensar na convergência de regulação estatal com complementação normativa privada, desde que a ideia matriz e finalidade essencial seja garantir o desenvolvimento social com a garantia e preservação da atividade lucrativa na consecução do bem-estar de toda a sociedade.

É sob essa perspectiva que se vislumbra na Responsabilidade Social da Empresa uma espécie de norma social, a qual, tal como os mecanismos de compliance, tem na sociedade o principal mecanismo de exigibilidade da conduta a ser observada pelas organizações.

Como consequência deste raciocínio que que se torna cada vez mais relevante a compreensão da dinâmica holística das atividades e de seus reflexos nas partes interessadas (stakeholders), ou seja, a RSE torna imprescindível que as organizações vislumbrem as consequências e os impactos direitos e indiretos de suas atividades no mercado.

O que se pode concluir é que a Responsabilidade Social das empresas vai muito além da criação de normas de conduta que estabeleçam comportamento socialmente aceitáveis. O que se pretende, é concatenar os interesses empresariais aos interesses da sociedade, de maneira que os impactos sociais da atividade econômica não sejam temas periféricos, mas centrais e fundamentalmente debatidos e resolvidos por todas as partes interessadas, de maneira a tornar a criação de valor compartilhado como o pressuposto do capitalismo. 


\section{REFERÊNCIAS}

ABBOTT, Kenneth W; SNIDAL, Duncan. Hard and Soft Law in International Governance. International Organization, v. 54, n. 3, p. 421-456, 2000. Disponível em:

https://www.cambridge.org/core/journals/international-organization/article/hard-and-soft-lawin-international-governance/EC8091A89687FDF7FC9027D1717538BF. Acesso em: 16 jun. 2020 .

ABNT. ISO. ABNT NBR 16001. Responsabilidade Social - Sistema de Gestão Requisitos. Disponível em:

http://www.inmetro.gov.br/qualidade/responsabilidade_social/index.asp. Acesso em 16 jun. 2020.

ABNT. ISO. ABNT NBR ISO 26000. Diretrizes sobre responsabilidade social. 2010. Disponível em:

http://www.pessoacomdeficiencia.gov.br/app/sites/default/files/arquivos/\%5Bfield_generico_i magens-filefield-description\%5D_65.pdf. Acesso em 16 jun. 2020.

ACEVEDO-GUERRERO, Javier Alejandro; ZARATE-RUEDA, Ruth; GARZON-RUIZ, Willian Fernando. Estatus jurídico de la responsabilidad social empresarial (rse) en Colombia. Díkaion, Chia, v. 22, n. 2, p. 303-332, 2013. Disponível em:

BRASIL. CÂMARA DOS DEPUTADOS. Comissão rejeita balanço social obrigatório para empresas. 06 maio 2010. Disponível em:

http://www2.camara.leg.br/camaranoticias/noticias/ECONOMIA/147526-COMISSAO-

REJEITA-BALANCO-SOCIAL-OBRIGATORIO-PARA-EMPRESAS.html. Acesso em: 16 jun. 2020.

BRASIL. Projeto de Lei no 3116 de 1997. Disponível em:

http://www.camara.gov.br/proposicoesWeb/fichadetramitacao?idProposicao=209785. Acesso em: 17 jun. 2020.

CARVALHO, Fernanda de Medeiros; SIQUEIRA, José Ricardo Maia de. Regulamentações brasileiras do balanço social. In: FERREIRA, Aracéli Cristina de Sousa et al. Contabilidade ambiental e relatórios sociais. São Paulo: Atlas, 2009. p. 23-41.

CLAVET, Rémi et al. Governance, International Law \& Corporate Social Responsibility. Genebra, International Labour Organisation, 2008. Disponível em: http://www.socialprotection.org/gimi/ShowRessource.action?ressource.ressourceId=33461. Acesso em: 16 jun. 2020.

DANTAS, Águida Jessica de Freitas; SIQUEIRA, Elisabete Stradiotto, NOBRE, Fábio Chaves, GIESTA, Lilian Caporlingua, SPERS, Valéria Rueda Elias. Responsabilidade social sob a ótica da ISO 26000: Uma Análise das Pequenas Empresas do Comércio Varejista de Mossoró/RN. Revista Perspectivas Contemporâneas, v. 11, n.2, p. 126-148, mai./ago. 2016. Disponível em:

http://revista.grupointegrado.br/revista/index.php/perspectivascontemporaneas/article/view/20 26/821. Acesso em: 16 jun. 2020.

GONÇALVES, Luísa Cortat Simonetti; PEDRA, Adriano Sant'Ana. Deveres internacionais e 
obrigações socioambientais para empresas multi e transnacionais. Revista de Direito Internacional, Brasília, v. 17, n. 3, p.519-537, 2020.

HARDIANA, Nadhira. Social Responsibility in ISO 26000 and Social Innovation. Atlantis Press, Paris, p.41-45, maio 2020. Disponível em: https://www.atlantispress.com/proceedings/isbest-19/125940888. Acesso em: 03 set. 2021.

HARTLAPP; Mirian; HOFMANN, Andreas. The use of EU soft law by national courts and bureaucrats: how relation to hard law and policy maturity matter, West European Politics, Londres, v. 44, 2020. Disponível em:

https://www.tandfonline.com/doi/abs/10.1080/01402382.2020.1738095?journalCode=fwep20 Acesso em: 03 ago. 2021.

HAYASHI, Janete Im. Governança corporativa e responsabilidade social: um estudo de avaliação da participação dos conselhos de administração no grau de responsabilidade social das empresas. 2020. Dissertação (mestrado profissional MPGC). Fundação Getúlio Vargas, São Paulo. 2020.

http://www.scielo.org.co/scielo.php?script=sci_arttext\&pid=S012089422013000200006\&lng =es\&nrm=iso. Acesso em: 16 jun. 2020.

INSTITUTO ETHOS. Indicadores Ethos para Negócios Sustentáveis e Responsáveis. 2002. Disponível em: https://www3.ethos.org.br/conteudo/indicadores/\#.Wyhf46dKg2w. Acesso em 16 jun. 2020.

INSTITUTO ETHOS. Práticas empresariais de responsabilidade social: relações entre os princípios do Global Compact e os indicadores Ethos de responsabilidade social. Carmen Weingrill. -- São Paulo: Instituto Ethos, 2003. Disponível em: https://www3.ethos.org.br/wpcontent/uploads/2012/12/18.pdf. Acesso em 16 jun. 2020.

KRAEMER, Maria Elisabeth Pereira. Responsabilidade social - uma alavanca para sustentabilidade. 2003, p. 1-16. Disponível em:

http://gerencia.ambientebrasil.com.br/midia/anexos/457.pdf. Acesso em: 17 jun. 2020.

LEITE, Fernanda Martins; SILVA, VanessA Ramos da; SANTOS, Cassius Klay Silva. Evidenciação Ambiental: Comparação entre a Capacidade Informacional dos Relatórios Contábeis de Companhias Brasileiras que Negociam ADR e as que Não Negociam. In: Anais... Congresso USP de Iniciação Científica em Contabilidade, 15. 2018, São Paulo: Universidade de São Paulo, 2018. Disponível em:

https://congressousp.fipecafi.org/anais/18UspInternational/ArtigosDownload/1185.pdf. Acesso em: 04 ago. 2021.

MACHADO, Pollyana; SILVA, Naiara Tavares. Modelos de balanço social no Brasil: um estudo comparativo. REASU - Revista Eletrônica de Administração da Universidade Santa Úrsula. v. 5 n. 1, 2020. Disponível em: http://200.251.23.33/index.php/REASU/article/view/1347. Acesso em 04 set. 2021.

MATTOS, Aliomar Lino; SILVA, Iris Bento da; ZATTA, Fernando Nascimento; GONZALEZ, Inayara V. D. Pedroso. Balanço Social: sua contribuição para as instituições financeiras. In: VIII Simpósio de Excelência em Gestão e Tecnologia. Associação Educacional Dom Bosco. Resende, RJ, 19-21 out. 2011. Disponível em: 
https://www.aedb.br/seget/arquivos/artigos11/22014728.pdf. Acesso em: 18 jun. 2020.

MATTOS, Nathália Soares de. A "due diligence" em direitos humanos e a responsabilidade social corporativa: duas faces da mesma moeda. In: MOREIRA, Angelina Colaci Tavares; BERTAZOLLI, Carolina Braglia Aloise; PAMPLONA, Danielle Anne Pamplona (org.). Atividade econômica e direitos humanos. Naviraí: Ipuvaíva Editora, 2020.

NOLAN, Justine. Hardening soft law: are the emerging corporate social disclosure laws capable of generating substantive compliance with human rights? Revista de Direito Internacional, Brasília, v. 15, n. 2, 2018 p. 64-83.

OLIVEIRA, Franciéle Fanaia de; LEITE, Rosamaria Cox Moura. As práticas de responsabilidade social de empresas modelo em sustentabilidade. Rev. Ciênc. Admin., Fortaleza, v. 20, n. 1, p. 249-284, jan./jun. 2014. Disponível em:

http://www.redalyc.org/html/4756/475647146009/. Acesso em 16 jun. 2020.

OLIVEIRA, José Antônio Puppim de. Empresas na sociedade: sustentabilidade e responsabilidade social. 2 ed. Rio de Janeiro: Elsevier: 2013.

OLIVEIRA, Liziane Paixão Silva; BERTOLDI, Márcia Rodrigues. A importância do soft law na construção do direito internacional ambiental. Revista do instituto do direito brasileiro, v. 1, n. 10, 2012. Disponível em:

https://www.cidp.pt/publicacoes/revistas/ridb/2012/10/2012_10_6265_6289.pdf. Acesso em: 16 jun. 2020.

OLIVEIRA, Mônica; FERREIRA, Marisa Roriz; LIMA, Vanda. Responsabilidade social corporativa: conceito, instrumentos de gestão e normas. Revista Brasileira de

Administração Científica, v. 6 n. 2, p. 161-172, 2015. Disponível em: http://sustenere.co/journals/index.php/rbadm/article/view/SPC2179684X.2015.002.0011. Acesso em 18 jun. 2020.

PACOBELLO, Daniella Ribeiro; BITTENCOURT, Josias Jacintho; BENEDICTO, Samuel Carvalho de; NEVES, Lívia Ferreira. Sustentabilidade, ética e responsabilidade social nas organizações: uma reflexão teórica. Brazilian Journal of Development, Curitiba, v.7, n.7, p.72666-72690, jul./2021. Disponível em:

https://www.brazilianjournals.com/index.php/BRJD/index. Acesso em 04 set. 2021.

PASCHKE, Megan. Corporate Responsibility in International Law. Denver Journal of International Law and Policy. 2019. Disponível em: http://djilp.org/corporateresponsibility-in-international-law/. Acesso em: 04 ago. 2021.

PENA, Roberto Patrus et al. Responsabilidade social empresarial e estratégia: um estudo sobre a gestão do público interno em duas empresas signatárias do global compact. Organ. Soc., Salvador, v. 14, n. 40, p. 81-98, mar. 2007. Disponível em http://www.scielo.br/scielo.php?script=sci_arttext\&pid=S198492302007000100005\&lng=en\&nrm=iso. Acesso em: 18 jun. 2020.

RIBEIRO, Maisa de Souza; PINTO; Anacleto Laurino. Balanço social: avaliação de informações fornecidas por empresas industriais situadas no Estado de Santa Catarina.

Revista Contabilidade \& Finanças - USP, São Paulo, n. 36, p. 21 - 34, set./dez. 2004. 
RUGGIE, John Gerard. The Social Construction of the UN Guiding Principles on

Business and Human Rights. Corporate Responsibility Initiative Working Paper n. 67. Cambridge, MA: John F. Kennedy School of Government, Harvard University. June 2017. p. $13-15$

SAURUGGER; Sabine; TERPAN; Fabien. Normative transformations in the European Union: on hardening and softening law, West European Politics, Londres, v. 44, 2020. Disponível em: https://www.tandfonline.com/doi/abs/10.1080/01402382.2020.1762440. Acesso em: 03 ago. 2021.

SHAFFER, Gregory; POLLACK, Mark A. Hard vs. Soft Law: Alternatives, Complements and Antagonists in International Governance (June 26, 2009). Minnesota Law Review, Vol. 94, pp. 706-99, 2010; Minnesota Legal Studies Research Paper No. 09-23. Disponível em: https://papers.ssrn.com/sol3/papers.cfm?abstract_id=1426123. Acesso em 16 jun. 2020.

SOUSA, Leila A; CORTÊS, Mauro Rocha. A Responsabilidade social empresarial e suas tentativas de normalização. XIII SIMPEP - Bauru, SP, Brasil, 6 a 8 de nov. de 2006. Disponível em: www.simpep.feb.unesp.br/anais/anais_13/artigos/770.pdf. Acesso em: 17 jun. 2020.

SOUZA, Herbert de. Balanço social: voluntário ou obrigatório? Folha de S. Paulo. São Paulo, 07 abr. 1997. Opinião. Disponível em: https://www1.folha.uol.com.br/fsp/opiniao/fz070409.htm. Acesso em: 17 jun. 2020.

YOUNG, Ricardo. Balanço social é responsabilidade do governo. Folha de S. Paulo. São Paulo, 29 mar. 1997. Mercado. Disponível em:

https://www1.folha.uol.com.br/fsp/1997/3/29/dinheiro/4.html. Acesso em: 16 jun. 2020. 